\title{
Results of the surgical treatment of perimedullary arteriovenous fistulas with special reference to embolization
}

\author{
Kazutoshi Hida, M.D., Yoshinobu Iwasaki, M.D., Katsuya Goto, M.D., Kazuo Miyasaka, M.D., and \\ Hiroshi Abe, M.D. \\ Departments of Neurosurgery and Radiology, University of Hokkaido, Sapporo, Japan; and Department \\ of Interventional Neuroradiology, Iizuka Hospital, Iizuka, Japan
}

This retrospective study was performed to evaluate the results of surgical treatment and the use of preoperative embolization in managing perimedullary arteriovenous fistulas (AVFs).

The authors studied 20 consecutive patients with perimedullary AVFs who underwent surgical treatment. Arteriovenous shunts were at the level of the cervical spine in five patients, the thoracic spine in 12, and the conus medullaris in three patients. Of the $20 \mathrm{AVFs}$, three were fed by the anterior spinal artery only, three by the posterior spinal artery, and 14 by both the anterior and posterior spinal arteries. Nine patients had varices that compressed the spinal cord. Eleven patients underwent surgery alone, and 9 patients underwent surgery combined with adjuvant preoperative embolization.

Preoperative embolization remarkably reduced the blood flow through AVFs and facilitated subsequent surgical procedures. Postoperative angiography revealed complete disappearance of the AVF in 16 patients. However, small fistulas persisted in the other four patients whose large lesions were fed by the anterior spinal artery. Neurological status was improved in 11 patients, unchanged in eight, and worse in one patient postsurgery.

Effective interruption of a spinal AV shunt was obtained by surgery in all cases, even when the anterior spinal artery was involved. For large and high-flow AVFs, embolization proved to be a useful adjunct to surgery.

Key Words * perimedullary arteriovenous fistula * spinal cord $*$ spinal arteriovenous malformation * embolization

Spinal perimedullary arteriovenous fistulas (AVFs), which are fed by the medullary arteries and are often associated with large varices, $[1-3,6-8,11,13]$ tend to be confused with intramedullary arteriovenous malformations (AVMs).[5] Recently, however, differential diagnosis of spinal AVMs has become more accurate because of the technological advancement of imaging diagnostic tools such as high-speed and high-resolution digital subtraction (DS) angiography, computerized tomography (CT) scanning, magnetic 
resonance (MR) imaging, and CT angiography. Additionally, accumulation of knowledge concerning the vascular anatomy of the spinal cord as well as development of microsurgical techniques have made these difficult spinal perimedullary AVFs a curable disease. $[1,2,5-9,11,12]$ However, the methods for treating spinal perimedullary AVFs are still controversial, especially regarding the surgical procedures.

In this paper, we present neuroradiological features of perimedullary AVFs, describe a strategy for treating them, and discuss the outcomes in our patients.

\section{CLINICAL MATERIAL AND METHODS}

\section{Patient Population}

Since 1981, we have treated 52 patients with spinal AVMs, 20 of whom had perimedullary AVFs that were surgically treated. The other 32 patients had intramedullary AVMs (nine patients) and dural AVFs (23 patients). The clinical data in the 20 patients with perimedullary AVFs are outlined in Table 1 . There were eight men and 12 women, and their ages ranged from 3 to 67 years (mean 37 years). Eleven patients showed acute aggravation of myelopathy due to subarachnoid hemorrhage or intramedullary hemorrhage. The other nine patients showed a gradual worsening of myelopathy, probably due to increased venous pressure and/or spinal cord compression by a venous varix. 


\begin{tabular}{|c|c|c|c|c|c|c|c|c|c|c|c|c|}
\hline \multirow{2}{*}{$\begin{array}{l}\text { Case } \\
\text { No. }\end{array}$} & \multirow{2}{*}{$\begin{array}{l}\text { Age } \\
\text { (ys }) \\
\text { Sex }\end{array}$} & \multirow{2}{*}{$\begin{array}{c}\text { Iribal } \\
\text { Symptom }\end{array}$} & \multirow{2}{*}{$\begin{array}{l}\text { Orset } \\
\text { of thy- } \\
\text { elopathy }\end{array}$} & \multirow{2}{*}{$\begin{array}{c}\text { Site } \\
\text { of AvF }\end{array}$} & \multirow{2}{*}{$\begin{array}{l}\text { Sub- } \\
\text { type } \\
\text { of AVF }\end{array}$} & \multirow{2}{*}{$\begin{array}{l}\text { ASA } \\
\text { Irr } \\
\text { volve } \\
\text { mert }\end{array}$} & \multirow[b]{2}{*}{ Treatment } & \multirow[b]{2}{*}{ Resuls } & \multicolumn{2}{|c|}{$\begin{array}{l}\text { LEVF } \\
\text { Sc ore }\end{array}$} & \multirow{2}{*}{$\begin{array}{c}\text { Last Fol- } \\
\text { low-Up } \\
\text { Angio- } \\
\text { graphy } \\
\text { (mos) }\end{array}$} & \multirow{2}{*}{$\begin{array}{l}\text { Re- } \\
\text { sidual } \\
\text { AV'F }\end{array}$} \\
\hline & & & & & & & & & Pre & Post & & \\
\hline 1 & 38, M & headache & acute & $C 2-3$ & IVa & yes & in terrupt & im pro ied & 2 & 3 & 12 & no \\
\hline 2 & $59, \mathrm{~F}$ & tetraparesis & acute & $\mathrm{c}-3$ & IVa & no & in terrupt & unchanged & 1 & 1 & 2 & no \\
\hline$\overline{3}$ & $62, F$ & tack pain & acute & $\mathrm{c}-3$ & IVa & yes & in terrupt & im pro ied & 4 & 5 & 42 & no \\
\hline 4 & $59, \mathrm{M}$ & rt leg numb & gradual & $\mathrm{T}-7$ & IVa & no & in terupt & im pro ied & 1 & 3 & 27 & no \\
\hline 5 & 26 , M & It leg meak & acute & T-8 & IVt & yes & in terrupt & im proved & 2 & 3 & 1 & no \\
\hline 6 & 56 , M & leg pain & gradual & $\mathrm{T}-9$ & IVb & yes & in terrupt & unchanged & 3 & 3 & 85 & no \\
\hline 7 & $3, F$ & leg pain & acute & T10-11 & IVc & yes & in terrupt & im pro ied & 1 & 3 & 8 & no \\
\hline 8 & 67 , M & $\begin{array}{l}\text { tilat legs } \\
\text { meak }\end{array}$ & gradual & $\mathrm{T}-11$ & IVt & yes & in terrupt & unchanged & 3 & 3 & 5 & no \\
\hline 9 & $23, \mathrm{~F}$ & back pain & acute & $\mathrm{T}-11$ & IVb & yes & in terrupt & im pro ved & 3 & 5 & 24 & no \\
\hline 10 & 33 , w & $\begin{array}{c}\text { tilat legs } \\
\text { numb }\end{array}$ & gradual & T12-L1 & IVt & yes & in terrupt & im pro ved & 3 & 5 & 1 & no \\
\hline 11 & $33, M$ & leg pain & gradual & T12-L1 & IVo & yes & in terrupt & unchanged & 2 & 2 & 2 & yes \\
\hline 12 & $34, F$ & headache & acute & $\mathrm{C}-6$ & IVt & yes & $\begin{array}{l}\text { embol \& } \\
\text { in terupt }\end{array}$ & unchanged & 3 & 3 & 23 & no \\
\hline 13 & $30, F$ & neck pain & acute & $\mathrm{C} 7-\mathrm{T} 1$ & IVb & yes & $\begin{array}{l}\text { embol \& } \\
\text { in terrupt }\end{array}$ & im pro ved & 3 & 4 & 13 & no \\
\hline 14 & $37, F$ & back pain & acute & $\frac{C-7, T-2,}{T-5}$ & IVC & yes & $\begin{array}{l}\text { em bol \& } \\
\text { in terrupt }\end{array}$ & worsened & 3 & 2 & 21 & yes \\
\hline 15 & $21, F$ & It leg numb & gradual & $T 7-8$ & IVt & no & $\begin{array}{l}\text { em bol \& } \\
\text { in terrupt }\end{array}$ & im pro ied & 2 & 3 & 12 & no \\
\hline 16 & $16, F$ & headache & acute & T8-9 & IVt & yes & $\begin{array}{l}\text { em bol } \& \\
\text { in terrupt }\end{array}$ & unchanged & 5 & 5 & 12 & yes \\
\hline 17 & $21, F$ & It leg weak & acute & T-9 & IVt & yes & $\begin{array}{l}\text { em bol \& } \\
\text { in terrupt }\end{array}$ & im pro ied & 2 & 3 & 13 & no \\
\hline 18 & $33, F$ & It leg weak & gradual & $\mathrm{T}-10$ & IVt & yes & $\begin{array}{l}\text { embol \& } \\
\text { in terrupt }\end{array}$ & im pro ied & 1 & 2 & 1 & no \\
\hline 19 & $34, F$ & $\begin{array}{l}\text { tilat legs } \\
\text { meak }\end{array}$ & gradual & $\mathrm{T}-11$ & IVo & yes & $\begin{array}{l}\text { embol \& } \\
\text { in terupt }\end{array}$ & unchanged & 3 & 3 & 29 & no \\
\hline 20 & $53, \mathrm{M}$ & $\begin{array}{c}\text { tilat legs } \\
\text { numb }\end{array}$ & gradual & $L-1$ & IVC & yes & $\begin{array}{l}\text { embol \& } \\
\text { in terupt }\end{array}$ & unchanged & 1 & 1 & 3 & yes \\
\hline
\end{tabular}

${ }^{* \mathrm{ASA}}=$ anterior spinal arter $\mathrm{y}_{1}$ em bol $=$ em bolization; interrupt $=$ interuption; post $=$ posttre atment; pre $=$ pretreatment.

\section{Radiological Findings}

Magnetic resonance imaging, superselective angiography, and CT angiography were used for diagnostic evaluation. The locations of the arteriovenous shunts were in the cervical spine (five patients), thoracic spine (12 patients), and the conus medullaris (three patients). Of the 20 AVFs, three were fed by the anterior spinal artery only, three by the posterior spinal artery only, and 14 by both arteries. Regarding the subtypes of AVF, $[2,6,8,11,12]$ there were four Type IVa, 11 Type IVb, and five Type IVc AVFs. Nine patients had varices that compressed the spinal cord.

\section{Surgical Treatment}

The goal of the surgical procedure is the interruption of the AV shunt. Eleven patients underwent surgery alone; the other nine patients underwent combined embolization and surgery.

Embolization was performed to reduce the flow of an AVF. In seven cases, we used polyvinyl alcohol (PVA) particles (Contour; Boston Scientific Co., Natick, MA) as an embolic material because we could 
not place the tip of a microcatheter close to the fistula, due to elongation and tortuosity of feeding pedicles. In two cases, we injected $N$-butyl-cyanoacrylate (NBCA) after successfully placing the tip of a microcatheter close the fistula.

Sixteen patients underwent operation via a posterior laminectomy; the other four underwent, via anterior approach, corpectomy of cervical vertebrae. During the operation, a microDoppler (model DVM-4200P; Nihon Kohden, Tokyo, Japan) was used to confirm the flow direction and pulsation of the vessels.

The clinical follow-up period after surgery ranged from 12 to 198 months, with a mean of 54 months. Follow-up angiography was scheduled immediately after surgery, at 1, 3, 12, and 24 months postsurgery.

\section{RESULTS}

\section{Surgical Outcome}

Preoperative embolization markedly reduced the blood flow to the AVFs and facilitated the subsequent surgical blood flow interruption in nine patients. Postsurgical control angiography showed complete disappearance of AVFs in 16 patients. Small residual fistulas were demonstrated in the other four patients who had large lesions that received blood from the anterior spinal artery.

Clinically, 11 patients improved, eight patients remain unchanged, and one worsened after surgery. The case of clinical worsening was thought to be due to damage caused to the draining vein during surgery. There were no symptomatic complications related to preoperative embolization in this series. Neurological status was evaluated pre- and posttreatment using scores of lower-extremity motor function[7] (Table 2). On average the scores improved from 2.4 pre- to 3.1 postoperatively.

\begin{tabular}{|c|c|}
\hline & $\begin{array}{c}\text { TABLE } 2 \\
\text { LOWER-EXTREMITY MOTOR FUNCTION SCORES* }\end{array}$ \\
\hline Sc ore & Description of Motor Function \\
\hline $\begin{array}{l}1 \\
2 \\
3 \\
4 \\
5\end{array}$ & $\begin{array}{l}\text { chair bound or bed ridden } \\
\text { needs support in walking, \& unable to ascend or descend stairs } \\
\text { dificulty walking, \& needs support to ascend or descend stairs } \\
\text { no difficulty malking, but mild difficul tyin ascending or descending stairs } \\
\text { normal walking, whor wh abnormal reflexes }\end{array}$ \\
\hline$\approx \mathrm{S}$ & and descriptions are taken from the Neurosurgical Cer wic \\
\hline
\end{tabular}

\section{ILLUSTRATIVE CASES}

\section{Case 5}

History. This 26-year-old man had experienced a sudden onset of headache during exercise when he was 14 years of age. Since then, he has experienced three subarachnoid hemorrhages, as well as progressive paraparesis and disturbances of bladder and bowel functions. An angiogram of the spine obtained while the patient was at another hospital revealed a spinal AVM. The patient was referred to our institute for surgical treatment.

Examination. On admission, the patient presented with spastic paraparesis that was more prominent on the left side, a bilateral Babinski's sign, hypalgesia and dysesthesia of the right lower extremity below the L-1 level, moderate gait disturbance, and bladder and bowel dysfunction. An MR image revealed multiple flow void around the mid- and lower thoracic spinal cord. Spinal arteriography demonstrated an 
intradural perimedullary AVF with varices that were fed by the posterior spinal artery, which came from the intercostal artery at the right T-9 level (Fig. 1 upper left). The participation intercostal artery at the left T-8 level was also noted through an anterior spinal artery (Fig. 1 upper right).

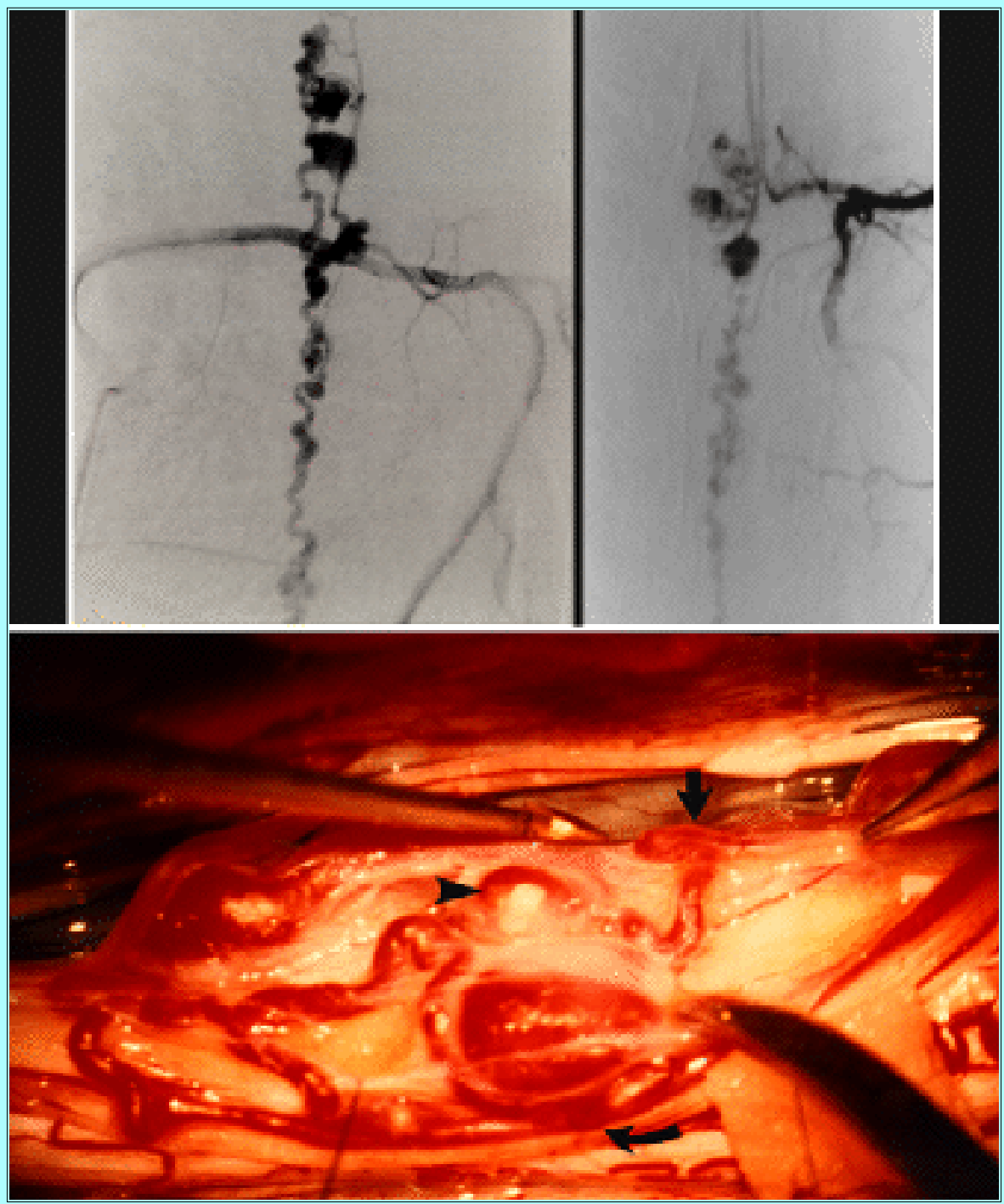

Fig. 1. Case 5. Imaging study. Upper Left: Spinal angiogram of intercostal artery at the right T-9 level, lateral view, demonstrating filling of posterior spinal artery, varix, and tortuous draining vein. Upper Right: Spinal angiogram of intercostal artery at the left T-8 level, anteroposterior view, showing filling of anterior spinal artery, varix, and tortuous draining vein. Lower: Intraoperative photograph showing that the posterior spinal artery (curved arrow) crossed three branches and merged into the point of AVF (arrowhead), and the lateral branch of anterior spinal artery (arrow) merged into the same point of the AVF.

Operation. A T7-10 thoracic laminectomy was performed. On opening of the dura mater, the arachnoid membrane showed slight adhesion to the spinal cord, which shifted to the left at the level of T8-9. After cutting the dentate ligaments, the spinal cord was rotated, and it was found that the posterior spinal artery diverged into three branches and merged into the fistulous point. A lateral branch of the anterior spinal artery also merged into the fistula via vasocorona (Fig. 1 lower). This fistulous point was coagulated. Postoperative angiography showed that the AVF had disappeared. The patient's gait improved significantly after the surgery. 
Examination. This 34-year-old woman suddenly experienced headache 5 months before admission. A spinal AVM was diagnosed in this patient, and she was transferred to our institute. On admission neurological examination, she was shown to have spastic paraparesis, which was dominant on the right side. An MR image revealed a flow-void area at the lower cervical cord. An angiogram of the spine in the segmental artery at the right C-7 level revealed a perimedullary AVF at the level of C 6-7 (Fig. 2A-C).

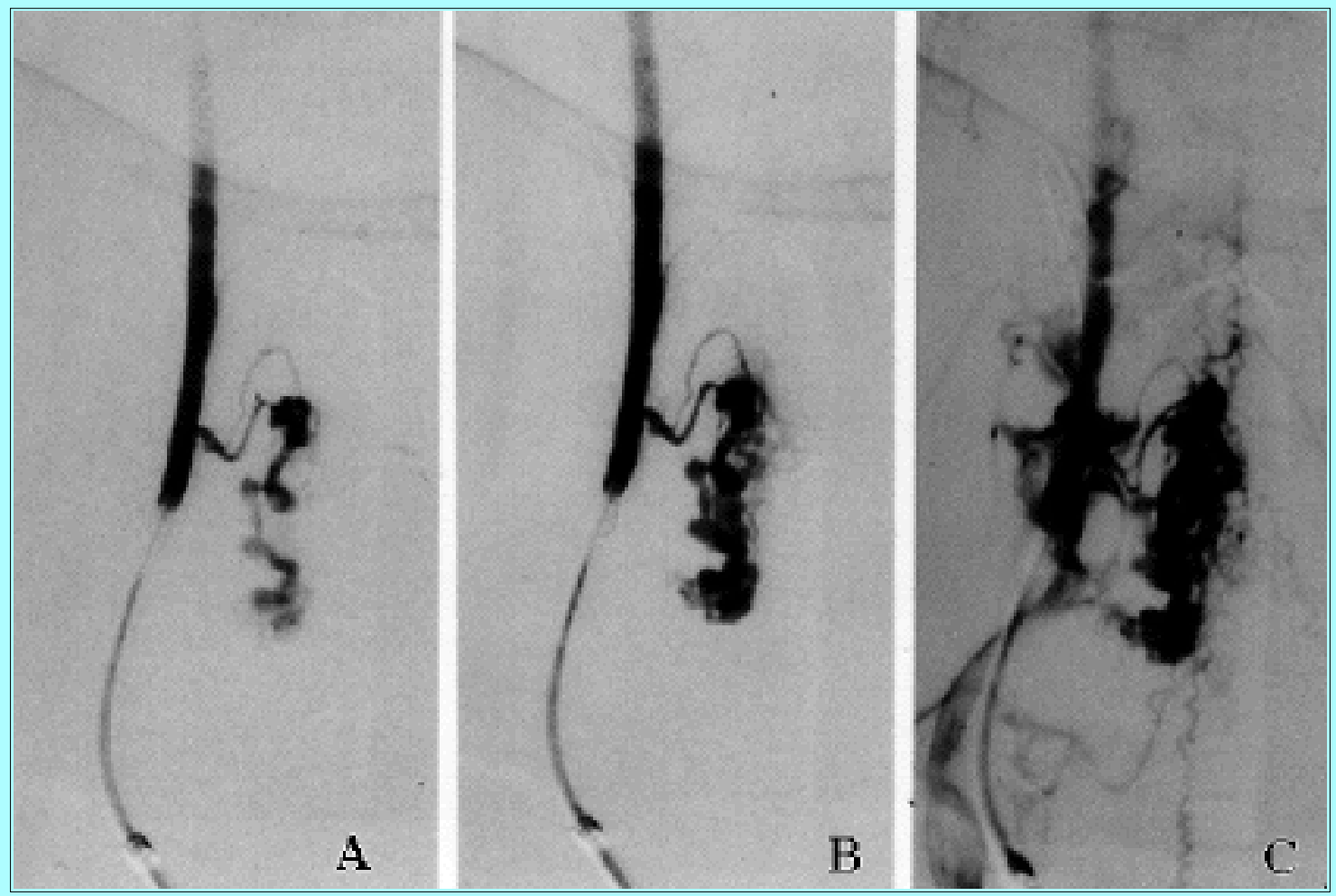

Fig. 2. Case 12. Angiograms of the segmental artery at the right C-7 level, anteroposterior view, showing a cervical perimedullary AVF. A: Early arterial phase. B: Midarterial phase. C: Late arterial phase. Note that the features of perimedullary AVF were obvious in the early arterial phase. In Fig. 2A note the fistulous point between the pial artery and the coronary venous plexus. In later arterial phase, differentiation from intramedullary AVM became difficult.

Embolization. Superselective cannulation of the radiculopial artery from right C-7 segmental artery was performed. Subsequent embolization was performed using a 1:1 mixture of NBCA and lipiodol. Contralateral vertebral angiography demonstrated a small residual AVF after embolization (Fig. 3 left). Further embolization was impossible; therefore, the patient underwent surgical interruption of the AVF. 


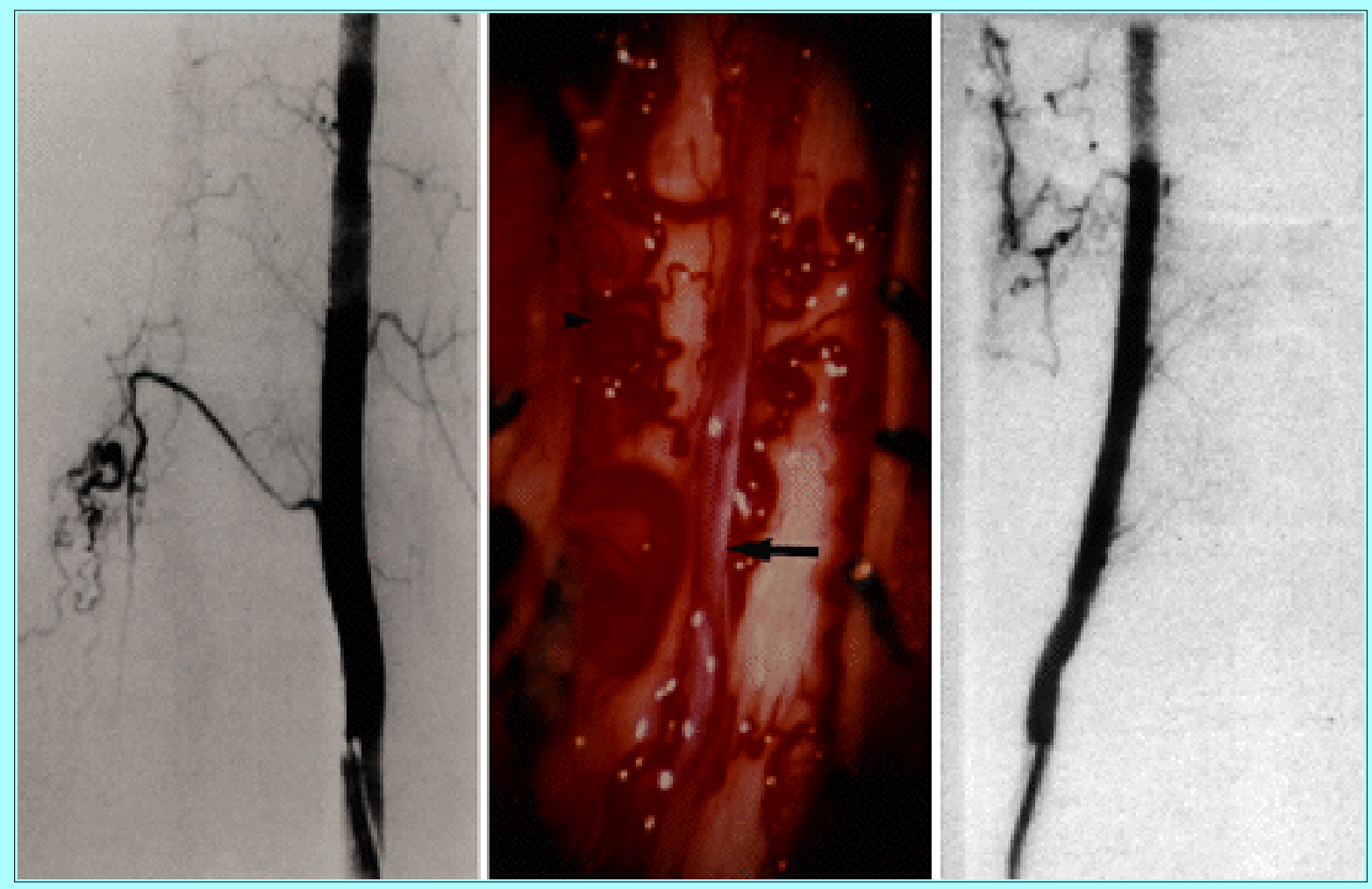

Fig. 3. Case 12. Imaging study. Left: Spinal contralateral vertebral artery angiogram, anteroposterior view, demonstrating a small residual AVF after embolization. Center: Intraoperative photograph showing the anterior spinal artery (arrow), feeding artery and fistulous point (arrowhead). Right: Postoperative spinal angiogram, anteroposterior view, demonstrating disappearance of the AVF.

Operation. Corpectomy of C-6 and C-7 via the anterior approach was performed. After opening the dura, the ventral surface of cervical cord was exposed and the anterior spinal artery, feeding artery, and fistulous point of the AVF were identified (Fig. 3 center). Subsequently, the fistulous point was coagulated. After closing the dura mater, iliac bone graft was inserted. The patient's gait disturbance improved slightly after surgery. Angiography of the spine 2 months after surgery demonstrated disappearance of the AVF (Fig. 3 right). On follow-up MR imaging 4 years after surgery no recurrent AVF was demonstrated.

\section{Case 13}

History. This 30-year-old woman complained of neck pain and numbness of the left lower extremity 3 years prior to her referral to our institution. On this earlier admission, she could not walk due to paraplegia that had developed within 1 month. She was diagnosed as having a perimedullary AVF at the level of C-7, which was fed by the right thyrocervical trunk via the anterior spinal artery (Fig. 4 upper left). Embolization was performed using PVA particles. The fistula was mostly obliterated, resulting in a marked reduction of the spinal cord edema. There was significant improvement in the patient's paraplegia; she started walking 1 month after embolization. However, an AVF from a tiny lateral branch of the anterior spinal artery remained (Fig. 4 upper right). She was referred to our institution in order to attain a complete cure. 


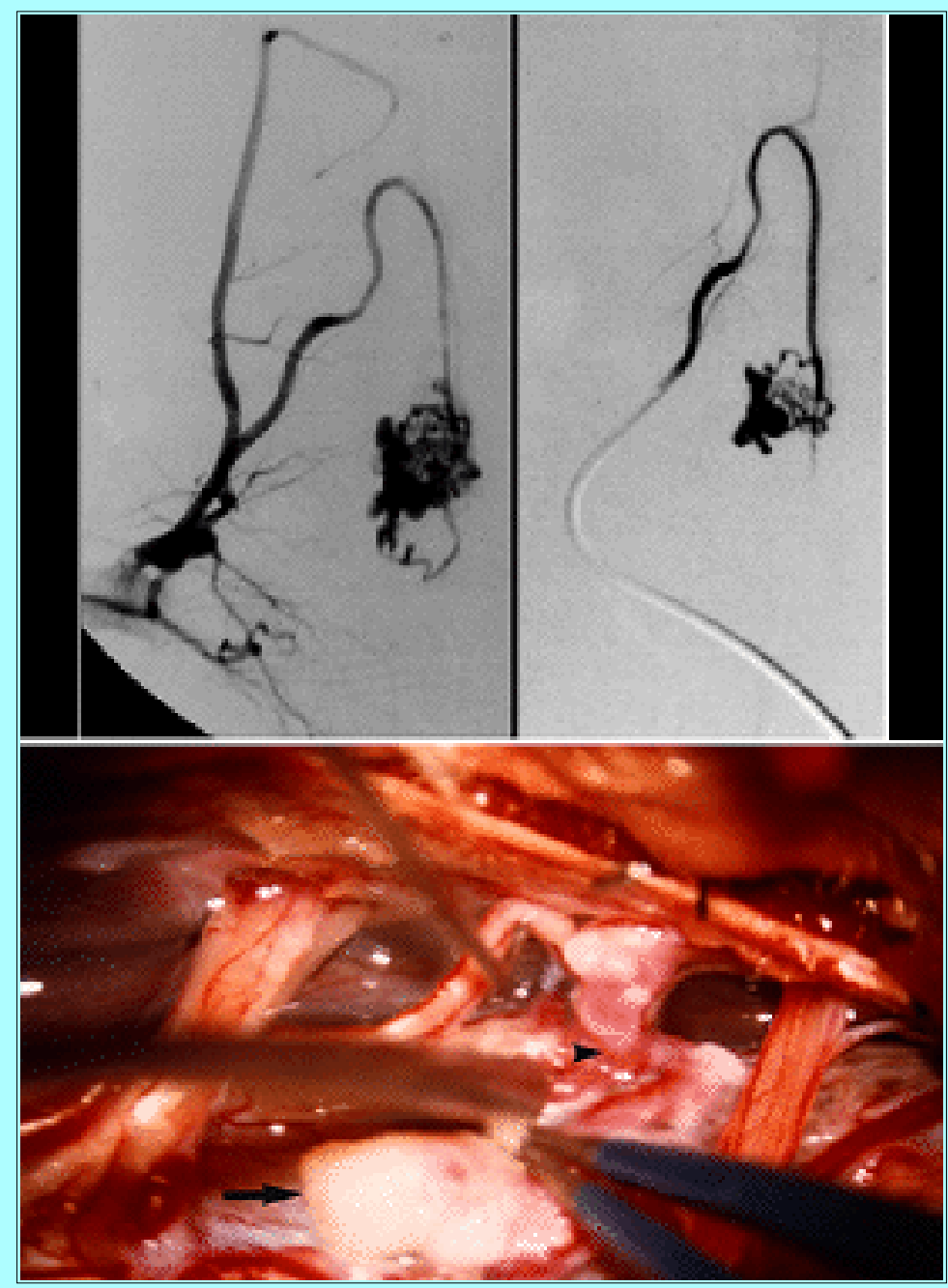

Fig. 4. Case 13. Imaging study. Upper Left: Spinal angiogram, anteroposterior view, of right thyrocervical trunk showing filling of anterior spinal artery and perimedullary AVF. Upper Right: Spinal angiogram of right thyrocervical trunk after partial embolization using PVA particles, showing occlusion of the major feeding branches from anterior spinal artery. Lower: Intraoperative photograph showing the fistulous point (arrowhead) and varix (arrow).

Examination and Operation. On admission neurological examination, the patient was shown to have spastic paraparesis that was dominant on the right side, ankle clonus, Babinski's and Chaddock signs on the right lower extremity, hypalgesia and hypesthesia of the left lower extremity, and bladder and bowel dysfunction. A C6-T1 laminectomy was performed. Intraoperatively it was seen that the AVF was fed by two small lateral branches that arose from the anterior spinal artery at the dorsolateral side of the spinal cord at the C-7 level. The AVF was identified and coagulated (Fig. 4 lower). The patient's neurological condition improved markedly immediately after surgery. Only a mild foot drop was noted on discharge 1 month after surgery. Postoperative angiography of the spine showed complete disappearance of the AVF.

\section{DISCUSSION}

\section{Classification of Spinal AVMs}

Classification of spinal AVMs is still controversial. Introduction of selective spinal arteriography in the 1960s contributed to the angiographic classifications of spinal AVMs based on vascular anatomy and the location of the abnormal arteriovenous shunt.[4] 
Spinal AVMs were recently classified into four types:[1,2,5-9,11,12] Type I is a long dorsal or dural spinal AVM; Type II, a compact or glomus lesion, usually intramedullary with multiple feeding vessels; Type III, a large juvenile malformation; and Type IV is a direct AVF on the surface of the spinal cord, without an intervening network of abnormal vessels (nidus).

The Type IV spinal cord AVM (the intradural perimedullary AVF) was first reported by Djindjian, et al.,[5] and it was further classified into three subtypes: 1) a simple extramedullary fistula fed by a single artery (Type IVa); 2) an intermediate-sized fistula with mono- or bipedicled feeding arteries and dilated drainage veins (Type IVb); and 3) giant fistulas with multipedicled arteries of large caliber and dilated large varix (Type IVc).[2,6,8,11,12]

\section{Vascular Anatomy}

Intensive investigation of the vascular anatomy in the human spinal cord has been performed.[14] It has been shown that the posterior spinal arteries are not a pair of trunks but, rather, a network of pial arteries that run medial and lateral to the dorsal root entry zone.[14] The anterior spinal artery and vein are located under thick pia mater, and the anterior spinal artery gives rise to sulcal arteries that travel in the anterior median sulcus and also to a few small-caliber lateral branches that travel over the anterior surface of the spinal cord.[14]

A Type IV spinal cord AVM, such as a perimedullary AVF that exists on the surface of the spinal cord, receives its blood supply from extramedullary pial arteries that arise from branches of the posterior spinal artery and/or the lateral branch of the anterior spinal artery. There is no participation of the sulcal artery as a feeding artery. In contrast, an intramedullary AVM, which is found in the spinal cord parenchyma, is fed by the sulcal artery and the medullary arteries arising from pial arteries.

\section{Diagnosis and Differential Diagnosis}

Varices are often associated with perimedullary AVFs.[3,6-8,11,13] In our series, nine (45\%) of 20 patients had varices that compressed the spinal cord. These varices are thought to be generated by two factors: venous hypertension and lack of intraparenchymal tissue pressure. Varices and enlarged lateralized draining veins often cause both a shift of the spinal cord and a deviation of the anterior spinal artery. Shift of the anterior spinal artery was observed in 10 of 20 patients with perimedullary AVFs, whereas the phenomenon was absent in nine patients with intramedullary AVMs in our series. Therefore, it might well be said that the existence of varices and/or a shift of the anterior spinal artery greatly favor the diagnosis of perimedullary AVF rather than intramedullary AVM.

Another important issue is how to identify the fistulous point in cases of perimedullary AVF. An abrupt change in the caliber of a blood vessel at the transition from feeding artery to draining vein is pathognomonic of the perimedullary AVF. Occasionally, however, this finding is obscured on conventional digital subtraction (DS) angiography by overlapping ectatic veins in cases with high-flow AVF. This is well recognized in the early arterial phase of high-speed (15-30 frames/second) and high resolution DS angiography (Fig. 4). The afore-mentioned technique is useful to rule out reflux filling of the intraparenchymatous venous structures that mimic the intramedullary nidus of an AVM. In some cases, however, differential diagnosis is possible only after embolization reduces the blood flow through the fistula (Fig. 4 center). Several lesions in our patients, initially thought to be intramedullary AVMs, were determined to be perimedullary AVFs based on radiological diagnosis or change in angiographic features after embolization. Based on our experience, we would like to point out a clinically important 
fact that a higher number of intradural AVMs than formerly thought are perimedullary AVFs, which are amenable to curative treatment.

\section{Treatment Options}

The goal of treatment is to interrupt the arteriovenous shunt by either surgery or embolization. We must also keep in mind that there are small artery-to-artery communications in perimedullary AVFs, especially in high-flow AVFs. Therefore, the interruption of the proximal side of a feeding artery is not enough to achieve complete cure of a perimedullary AVF. Another important aspect of treatment is to interrupt the arteriovenous shunt while preserving normal perfusion of the spinal cord.

Initially, perimedullary AVFs were treated by surgery with clips.[5] Subsequently, embolization alone[1,6,7] as well as combined treatment with embolization and surgery were reported.[1,6,7,11,13] The selection of treatment in perimedullary AVFs is still controversial; currently recommended therapies include surgery alone[2,9] and embolization using particles, six balloons,[11,12] or balloons in combination with surgery.[6,7]

Endovascular therapy has been suggested as the primary therapy in large AVFs.[6] Halbach, et al.,[7] reported that those patients in whom occlusion was incomplete were difficult cases because the fistula was located on the anterior surface of the cord and was fed mainly by the anterior spinal artery.[7]

As a preoperative embolic agent, PVA particles are safe and effective if appropriate-sized particles are used. In humans, the diameter of the normal sulcocommissural arteries varies from 60 to $72 \mu \mathrm{m}$, and the diameter of normal anterior spinal artery ranges from 340 to $1100 \mu \mathrm{m}$.[1] Therefore, embolization via the anterior spinal artery using embolic particles smaller than $100 \mu \mathrm{m}$ would be dangerous.[1] In our institute, 250 to 350- $\mu$ m PVA particles were most frequently used. However, depending on the size of the fistula, 350 to $500-\mu \mathrm{m}, 500$ to $710-\mu \mathrm{m}$, or even 710 to $1000-\mu \mathrm{m}$ PVA particles were used.

The benefits of preoperative embolization are the reduction of blood flow through the fistula and the use of artificial emboli as an intraoperative visible landmark of the fistula. Successful embolization thus made the surgery much easier in our patients.

Liquid adhesives (such as NBCA) are a more powerful embolic material than PVA particles, but this agent must be accurately deposited in the fistulous point so as not to obstruct the perfusion of normal spinal cord tissue. In clinical practice, it is often difficult to advance a microcatheter close enough to the fistulous point due to the tortuosity of elongated feeding pedicles. In most cases, therefore, surgical interruption at the fistulous point is the ideal treatment to achieve complete cure.

Barrow, et al.,[2] have reported that in eight patients with perimedullary AVF, seven AVFs were surgically obliterated.[2]

A proximal ligation of arterial supply of spinal cord AVMs can produce only temporary benefit by forming multiple small collateral branches to the AVMs. The key points of the surgical procedure are for the surgeon to interrupt the point of the arteriovenous shunt only, preserve the draining vein on the spinal cord, and coagulate and shrink the varix if it compresses the spinal cord. During operation, microDoppler ultrasonography is very useful to confirm the flow direction and pulsation of the vessels.

\section{CONCLUSIONS}

It is important to diagnose perimedullary AVF correctly; occasionally, differentiation from 
intramedullary AVMs is achieved only by evaluation of a meticulous neuroradiological workup. It is also important to identify the fistulous point in cases of perimedullary AVF. The optimum management of perimedullary AVF is to interrupt the arteriovenous shunt. An effective interruption of a perimedullary AVF can be achieved by surgery, regardless of involvement of the anterior spinal artery. Preoperative embolization is useful for large and high-flow perimedullary AVFs.

\section{References}

1. Bao YH, Ling F: Classification and therapeutic modalities of spinal vascular malformations in 80 patients. Neurosurgery 40:75-81, 1997

2. Barrow DL, Colohan ART, Dawson R: Intradural perimedullary arteriovenous fistulas (Type IV spinal cord arteriovenous malformations). J Neurosurg 81:221-229, 1994

3. Biondi A, Merland JJ, Hodes JE, et al: Aneurysms of spinal arteries associated with intramedullary arteriovenous malformations. I. Angiographic and clinical aspects. AJNR 13:913-922, 1992

4. Di Chiro G, Doppman JL, Ommaya AK: Selective arteriography of arteriovenous aneurysm of spinal cord. Radiology 88:1065-1077, 1967

5. Djindjian M, Djindjian R, Rey A, et al: Intradural extramedullary spinal arterio-venous malformations fed by the anterior spinal artery. Surg Neurol 8:85-93, 1977

6. Gueguen B, Merland JJ, Riche MC, et al: Vascular malformations of the spinal cord: intrathecal perimedullary arteriovenous fistulas fed by medullary arteries. Neurology 37:969-979, 1987

7. Halbach VV, Higashida RT, Dowd CF, et al: Treatment of giant intradural (perimedullary) arteriovenous fistulas. Neurosurgery 33:972-980, 1993

8. Hamilton MG, Anson JA, Spetzler RF: Arteriovenous and other vascular malformations of the spine, in Menezes AH, Sonntag VK (eds): Principles of Spinal Surgery. New York: McGraw-Hill, 1996, Vol $2,1423-1451$

9. Heros RC, Debrun GM, Ojemann RG, et al: Direct spinal arteriovenous fistula: a new type of spinal AVM. Case report. J Neurosurg 64:134-139, 1986

10. Kadoya S: Grading and scoring system for neurological function in degenerative cervical spine disease--Neurosurgical Cervical Spine Scale. Neurol Med Chir 32:40-41, 1992

11. Mourier KL, Govin YP, George B, et al: Intradural perimedullary arteriovenous fistulae: results of surgical and endovascular treatment in a series of 35 cases. Neurosurgery 32: 885-891, 1993

12. Riche MC, Reizine D, Melki JP, et al: Classification of spinal cord vascular malformations. Radiat Med 3:17-24, 1985

13. Takahashi H, Morita A, Ishijima B, et al: [An infant case of spinal arteriovenous malformation with a large venous aneurysm.] No Shinkei Geka 20:509-514, 1992 (Jpn)

14. Tator CH, Koyanagi I: Vascular mechanism in the pathophysiology of human spinal cord injury. J Neurosurg 86:483-492, 1997 
Manuscript received August 18, 1998.

Accepted in final form September 29, 1998.

This paper was presented, in part, at the Annual Meeting of the American Association of Neurological Surgeons, Minneapolis, Minnesota, April 27, 1996.

Address reprint requests to: Kazutoshi Hida, M.D., Department of Neurosurgery, University of Hokkaido, School of Medicine, North 15, West 7, Sapporo 060-0919, Japan. email:

kazuhida@med.hokudai.ac.jp. 